\title{
A influência da educação popular freireana na Associação dos Moradores e Amigos do Bairro Itinga em Joinville/SC
}

DOI: https://doi.org/10.22409/pragmatizes.v12i22.51467

\section{Charles Henrique Voos ${ }^{1}$ Bruna Eloize Taborda Ribas ${ }^{2}$}

Resumo: Considerando a atual conjuntura política nacional e a crescente onda neoliberal conservadora, que aliena e ameaça os direitos dos cidadãos, objetivou-se com este trabalho explorar a temática da educação popular sob a visão de Paulo Freire, e buscou-se fazer a relação entre esta teoria e as práticas realizadas na Associação de Moradores e Amigos do Bairro Itinga, a Amorabi. Para tanto, foi realizado uma pesquisa bibliográfica e um resgate histórico sobre a associação, bem como coleta de entrevistas e imagens que ilustrassem esta trajetória. Também foi analisada a importância e relevância dos projetos da Amorabi para a comunidade. Concluiu-se que a Associação, desde sua fundação realiza uma ação política que condiz muito ao que propunha Paulo Freire, e que as atividades realizadas na e pela Amorabi tem em Freire uma influência direta e indireta.

Palavras-chave: Educação popular; Paulo Freire; política; cultura popular.

La influencia de la educación popular freireana en la Asociación de Residentes y Amigos del Barrio Itinga En Joinville/SC

Resumen: Considerando la actual coyuntura política nacional y la creciente ola neoliberal conservadora, que aliena y amenaza los derechos de los ciudadanos, el objetivo de este trabajo fue explorar el tema de la educación popular desde el punto de vista de Paulo Freire, y buscó hacer la relación entre esta teoría y las prácticas realizadas en la Asociación de Residentes y Amigos del Barrio Itinga, Amorabi. Para ello, se realizó una búsqueda bibliográfica y una revisión histórica de la asociación, así como la recopilación de entrevistas e imágenes que ilustran esta trayectoria. También se analizó la importancia y relevancia de los proyectos de Amorabi para la comunidad. Se concluyó que la Asociación, desde su fundación, ha realizado una acción política muy en línea con lo propuesto por Paulo Freire, y que las actividades realizadas en y por Amorabi tienen una influencia directa e indirecta en Freire.

Palabras clave: Educación popular; Paulo Freire; política; cultura popular.

\footnotetext{
${ }^{1}$ Charles Henrique Voos. Doutor em Sociologia pela Universidade Federal do Rio Grande do Sul. Professor da Faculdade Guilherme Guimbala - Joinville/SC, Brasil. charleshenriquevoos@gmail.com - https://orcid.org/0000-0003-3170-744X

${ }^{2}$ Bruna Eloize Taborda Ribas. Licenciada em Pedagogia pela Faculdade Guilherme Guimbala Joinville/SC, Brasil. brunaribas23@gmail.com - https://orcid.org/0000-0002-5699-7415
} 
The influence of Freire's popular educational in the Association of Residents and Friends of Itinga's Neighborhod in Joinville/SC

Abstract: Considering the current national political situation and the growing conservative neoliberal wave, which alienates and threatens the rights of citizens, this work aimed to explore the theme of popular education from the perspective of Paulo Freire, and sought to make the relationship between this theory and practices carried out in the Association of Residents and Friends of the Itinga's Neighborhood, Amorabi. Therefore, a bibliographic research and a historical review of the association were carried out, as well as interviews and images were collected to illustrate this trajectory. The importance and relevance of Amorabi's projects for the community was also analyzed. It was concluded that the Association, since its foundation, carries out a political action that is very consistent with what Paulo Freire proposed, and that the activities carried out in and by Amorabi have a direct and indirect influence on Freire.

Keywords: Popular education; Paulo Freire; politics; popular culture.

\section{A influência da educação popular freireana na Associação dos Moradores e Amigos do Bairro Itinga em Joinville/SC}

\section{Introdução}

A educação formal é como é atualmente, devido a um longo processo histórico que envolve questões sociais, políticas e econômicas, e que, apesar disso, ainda se encontra presa a valores ultrapassados e autoritários. As possibilidades de acesso e de qualidade educacional variam muito, a depender da classe econômica dos estudantes. Mesmo que nas últimas décadas a educação nacional tenha caminhado a passos lentos para reduzir as desigualdades existentes, por meio de políticas públicas conquistadas com muita luta popular, o atual cenário político vem acarretando retrocessos preocupantes.

A especialista em alfabetização Magda Soares, em uma entrevista para a revista Nova Escola, afirmou que, mesmo tendo mais de 60 anos de experiência na educação, nunca viveu um período tão assustador quanto o atual (SEMIS, 2019). Isto porque a ascensão do pensamento neoliberal ultraconservador na política, e consequentemente na população, tem afetado diretamente 0 campo educacional, e inclusive, atacado explicitamente um dos principais contribuintes da luta por uma 


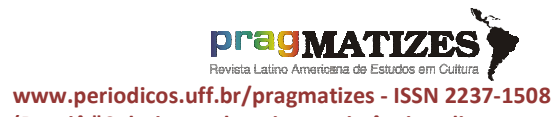

(Dossiê "Coletivos culturais - resistências, disputas e potências") educação mais justa e igualitária, Paulo Freire.

A educação proposta por Paulo Freire é uma educação libertadora, que busca desvelar a realidade, romper com mitos estabelecidos pelas elites opressoras e resgatar a humanidade das pessoas. Os conteúdos precisam dialogar com a vida cotidiana, com a realidade e interesses dos estudantes, e o educador deve assumir o papel de mediador destes conhecimentos, sempre através do diálogo problematizador, buscando a superação de todas as formas de violência.

A escolha do tema da educação popular ocorreu justamente pela necessidade de se pensar em formas de educação baseadas nos princípios freireanos, reforçando a sua importância para a sociedade como um todo, buscando exemplos reais, que dão certo, e que façam parte da cidade de Joinville.

O local escolhido para realizar esta pesquisa foi a Associação de Moradores e Amigos do Bairro Itinga (Amorabi), onde desde 1981 a educação é o principal alicerce para a busca de melhorias e transformações sociais através do engajamento popular nas mais diversas atividades.

Localizada em uma região periférica da cidade, a Amorabi atinge hoje um público de crianças, adolescentes e adultos, muitos em situação de vulnerabilidade social, com atividades culturais e educativas, como teatro, capoeira, cursinho prévestibular, entre outras, todas oferecidas gratuitamente através de trabalho voluntário e projetos de incentivo público (editais).

No presente trabalho buscou-se pensar a Educação Popular não como um método, mas como uma filosofia educacional, como um processo revolucionário, que exige reflexão crítica, exige pesquisa e rigor metodológico, mas também exige respeito aos saberes do educando, exige liberdade, alegria e esperança (FREIRE, 2016). Pretendeu-se investigar a relação do pensamento freireano com as ações da Amorabi e qual a sua importância para a comunidade.

Para embasar cientificamente esta pesquisa, além de estudos da bibliografia de Paulo Freire, foi realizado um balanço de produção acadêmica nos portais da Scielo 
(Scientific Electronic Library Online) e da Anped (Associação Nacional de Pós-Graduação e Pesquisa em Educação), onde pesquisou-se dez artigos publicados dentro do tema escolhido, neste caso a Educação Popular.

\section{Produziu-se um resgate} histórico acerca da resistência e da educação popular da Amorabi, tendo como fontes as entrevistas realizadas com os educadores, e também o livro "O Teatro em Comunidades Periféricas", de Cristóvão Petry. Depois, mais especificamente, relatouse sobre algumas atuações no Residencial Trentino, através dos relatos das entrevistas de educadores e alunos, bem como as imagens coletadas com auxílio do Roteiro de Análise Documental, e por fim foi realizada a análise do tema, fazendo a relação entre as práticas da Amorabi e a teoria de educação freireana.

\section{A Pedagogia de Paulo Freire}

Paulo Freire ficou conhecido como um dos mais importantes educadores do século $X X$, por criar um método de alfabetização, que, aliado ao pensamento crítico, à leitura, e à interpretação do mundo, foi capaz de alfabetizar 300 trabalhadores adultos em 40 horas. Neste método, Freire partia de palavras geradoras que faziam parte do cotidiano dos alunos. Palavras como tijolo, máquina, farinha, e conceitos de trabalho e pobreza eram contextualizados e debatidos. Com a divisão das sílabas, os estudantes aprendiam a ler cada palavra e em seguida aprendiam as famílias silábicas, para formar novas palavras (BURLAN, 2019).

Porém, toda a contribuição de Paulo Freire para a educação e diversas áreas do conhecimento vai muito além do método. Freire colocou a educação a serviço da justiça social, da transformação, da emancipação e da liberdade. Para ele, o conhecimento deveria ser acessível a todos, sem distinções, e partir sempre da realidade dos sujeitos, onde todo conteúdo deve ser dialogado e problematizado de forma horizontal, tendo o educador a humildade de aprender com os conhecimentos de vida e cultura dos estudantes.

Como um compromisso político com aqueles que se encontram a margem da sociedade, a educação proposta por Freire deve conter a ação dialógica, tendo como objetivo "[...] 
proporcionar que os oprimidos, Porém a escola em si não é o reconhecendo o porquê e como de sua 'aderência', exerçam um ato de adesão à práxis verdadeira de transformação da realidade injusta" (FREIRE, 2012, p. 184).

A escola regular, de uma forma generalizada, está longe de praticar sistematicamente a Pedagogia de Paulo Freire, ainda que inclua em seus Planos Políticos Pedagógicos diversas citações do autor. Freire era um crítico rigoroso do que ele chamou de educação bancária, que é esta onde os conhecimentos são transferidos de forma autoritária e meritocrática, perpetuando diversos mitos criados pela elite com intuito manipulatório, sob falso discurso de neutralidade. Segundo ele, esta forma de educação está a serviço da manutenção do status quo, das opressões da elite sobre os trabalhadores, onde os conteúdos não dialogam com a vida dos estudantes, e onde seus conhecimentos prévios são praticamente ignorados. Transformar esse quadro fica a serviço dos professores em "chão de sala", enquanto a estrutura educacional como um todo não for realmente reformulada. único local de aprendizado, de educação. A própria LDB, em seu artigo $1^{\circ}$ diz que:

A educação abrange os processos formativos que se desenvolvem na vida familiar, na convivência humana, no trabalho, nas instituições de ensino e pesquisa, nos movimentos sociais e organizações da sociedade civil e nas manifestações culturais. (BRASIL, 1996).

$E$ é neste sentido que este trabalho buscará ampliar as noções de educação, trazendo visibilidade para a importância da participação popular nos processos educativos, e como locais fora da escola podem contribuir para a formação de cidadãos conscientes e críticos de sua realidade, através do que podemos chamar de Educação Popular.

\section{A Educação Popular}

A educação é um projeto político, que dependendo a serviço de qual classe ela está, pode manipular e alienar, mas também pode ser libertadora e humanizadora, dentro e fora da escola. A ideia de educação popular surge a partir da crítica à educação alienante, e propõe despertar o potencial dos estudantes e 
da comunidade para criar alternativas libertárias à lógica de opressão do capital. Um processo coletivo que articula o saber popular e o científico, tendo como ponto de partida a realidade local e concreta dos participantes.

Não existe uma definição única para o conceito de Educação Popular, mas pode-se afirmar que ela é uma construção histórica fundamentada em muito estudo e trabalho de base.

A década de 1960, no Brasil, foi um marco do surgimento do que se podem chamar movimentos de cultura popular, que consistiam em atuações educacionais organizadas e promovidas por movimentos sociais com apoio do Estado, que buscavam a valorização dos saberes populares, das tradições, das músicas, das medicinas naturais etc.

A história da educação popular geralmente é contada a partir da década de 1960, que no Brasil coincide com uma forte mobilização popular na qual se encontrava inserida a educação, em especial a alfabetização de adultos. A referência mais marcante desse movimento pedagógico-político-cultural é o projeto de Paulo Freire em Angicos, no Rio Grande do Norte, em 1963. (STRECK, 2010, p. 301)
A história da educação popular no Brasil e a história de Paulo Freire se misturam, pois toda a visão pedagógica, política e ética deste professor contribuiu para a consolidação da forma de pensar a educação popular, que hoje ainda se encontra em processo de construção.

Após o golpe militar de 1964, a educação passou por fortes transformações, onde muitos movimentos sociais que eram responsáveis pelas iniciativas de educação popular foram criminalizados, e Freire foi exilado do país. Durante este período até a década de 1980, a educação popular acontecia através dos trabalhos de base dos movimentos sociais, que tinha como sua principal meta a conscientização dos trabalhadores sobre sua condição de explorados, e a crítica ao governo ditatorial.

$\mathrm{Na}$ década de 1990, o país inicia seu processo de redemocratização, e a educação passa a assumir constitucionalmente novas perspectivas. Segundo Gohn (2017, p.30),

a educação popular desempenhou diferentes papéis junto ao sujeito coletivo "movimento social", ora atuando 
como agente de formação e conscientização (décadas de 1970-1980), ora atuando via o 'empowerment' da comunidade visando a processos de inclusão social (1990-2010), ora sendo recriada pelos movimentos dos indignados nas marchas e manifestações da atualidade (década de 2010 em curso).

Atualmente, a educação popular ainda opera nas comunidades do campo, como é o caso do Movimento dos Trabalhadores Rurais Sem Terra (MST), ou nas periferias das grandes cidades, através de movimentos sociais e organizações diversas, mas também mais do que nunca, busca se recontextualizar, e resistir frente ao cenário político e social em que o Brasil se encontra, onde o pensamento de Paulo Freire é repudiado pelos principais líderes governamentais, e onde qualquer método educacional voltado para o pensar crítico e valorização da cultura popular é perseguido e rechaçado pelo governo neoliberal, com apoio de uma parcela da população.

Para se manter viva e ser libertadora, a educação precisa da ação política, precisa se concretizar através de ações culturais que partam dos símbolos e dos significados das próprias raízes culturais populares da comunidade na qual se está trabalhando. Todo e qualquer pensamento opressor, classista e sexista, deve ser problematizado e dialogado, buscando a superação de crenças e mitos naturalizados pela sociedade, estabelecidos pelas elites opressoras.

Nas palavras de Paulo Freire:

[...] a Educação Popular pode ser socialmente percebida como facilitadora da compreensão científica que grupos e movimentos podem e devem ter acerca de suas experiências. Esta é uma das tarefas fundamentais da educação popular de corte progressista, a de inserir os grupos populares no movimento de superação do senso comum pelo conhecimento mais crítico, mais além do "penso que é", em torno do mundo e de si no mundo e com ele. (FREIRE, 2014, p. 35).

Com base nestes conhecimentos aqui resumidos, buscar-se-á resgatar a importância e urgência da educação popular em todos os espaços, na perspectiva da atual conjuntura e partindo de uma experiência concreta que acontece na cidade de Joinville.

\section{Metodologia}

A presente pesquisa realizada possui caráter descritivo, pois segundo 
Antônio Gil, a pesquisa descritiva é aquela que tem como objetivo

\begin{abstract}
a descrição das características de determinada população ou fenômeno ou o estabelecimento de relações entre variáveis. São inúmeros os estudos que podem ser classificados sob este título e uma de suas características mais significativas está na utilização de técnicas padronizadas de coleta de dados. (GIL, 2008, p. 28)
\end{abstract}

No que se refere aos métodos de investigação, foi realizada uma pesquisa de campo, que consiste em estudar "um único grupo ou comunidade em termos de sua estrutura social, ou seja, ressaltando a interação de seus componentes" (GIL, 2008, p. 57), e juntamente com as observações em campo foi utilizado o método de pesquisa documental, onde são realizadas análises de "materiais que não receberam ainda um tratamento analítico, ou que ainda podem ser reelaborados de acordo com os objetivos da pesquisa" (GIL, 2008, p. 51), como por exemplo, reportagens de jornal, fotografias, gravações, etc. e também a aplicação de questionários (entrevistas).

O local escolhido para realizar esta pesquisa foi a Associação de Moradores e Amigos do Bairro Itinga (Amorabi), que oferece gratuitamente para a comunidade diversas atividades culturais educativas como teatro, capoeira, cursinho pré-vestibular, corte e costura, entre outras.

Para realizar a coleta dos dados nesta pesquisa, serão utilizadas duas ferramentas: Roteiro de Entrevista e Roteiro de Análise Documental (encontram-se no apêndice). Devido a pandemia de Covid-19 e a necessidade do distanciamento social, as perguntas foram enviadas via mensagem, e respondidas através de áudios. Três professores e três alunos que participam das atividades da associação responderam

questionário.

Com base na análise dos dados coletados através destes procedimentos metodológicos, pretende-se buscar a relação existente entre a pedagogia freireana $e$ as práticas da associação.

\section{Amorabi: 40 Anos de Educação e} Luta

O bairro Itinga é situado na região extremo sul de Joinville, em divisa com o município de Araquari, estando a quilômetros de distância do centro urbano e das principais indústrias da cidade, portanto, um 
bairro periférico. Relativamente novo em termos legais, o bairro Itinga foi oficialmente criado em 1977, e ainda hoje possui alguns aspectos rurais, devido a seus processos colonizatórios, mas isso não significa que na região não exista pluralidade cultural. Conforme Freire (2014, p. 28): "A Cidade é cultura, é criação, não só pelo que fazemos nela e dela, pelo que criamos nela e com ela, mas também é cultura pela própria mirada estética ou de espanto, gratuita, que Ihe damos. A Cidade somos nós e nós somos a Cidade".

Onde o poder público não investe, o povo se organiza, e foi dessa forma que nasceu a Associação de Moradores e Amigos do Bairro Itinga, no ano de 1981.

Segundo Cristóvão Petry, Mestre em Teatro pela UDESC e expresidente da associação, além de ter sido sediada em unidades escolares, a Amorabi sempre esteve ligada à luta pela educação.

A Amorabi se destacou por ter sido porta-voz da comunidade em importantes vitórias como a construção do CEI Eliane Kruguer (bairro Boehmerwald) e CEI Pedro Paulo Hings Colin, conquista do terreno para a construção da nova sede da Escola Municipal Lacy Luiza da Cruz Flores [...] criou o primeiro centro de Educação Infantil no Itinga chamado Centro Comunitário de Educação Infantil - Cecei Vovó Juliana. (PETRY, 2020, p. 28)

Atualmente, a associação cede - andar térreo de seu prédio (construído pelos moradores através de mutirões) para o CEI Vovó Juliana, que em 2013 foi assumido pela Secretaria Municipal de Educação, após muitos anos de organização comunitária e luta para continuar atendendo as famílias da comunidade. 
Figura 1 - Construção voluntária da sede que hoje possui salas de aula, cozinha, banheiros, biblioteca, arquibancada e palco no andar de cima, e o CEI no andar térreo.

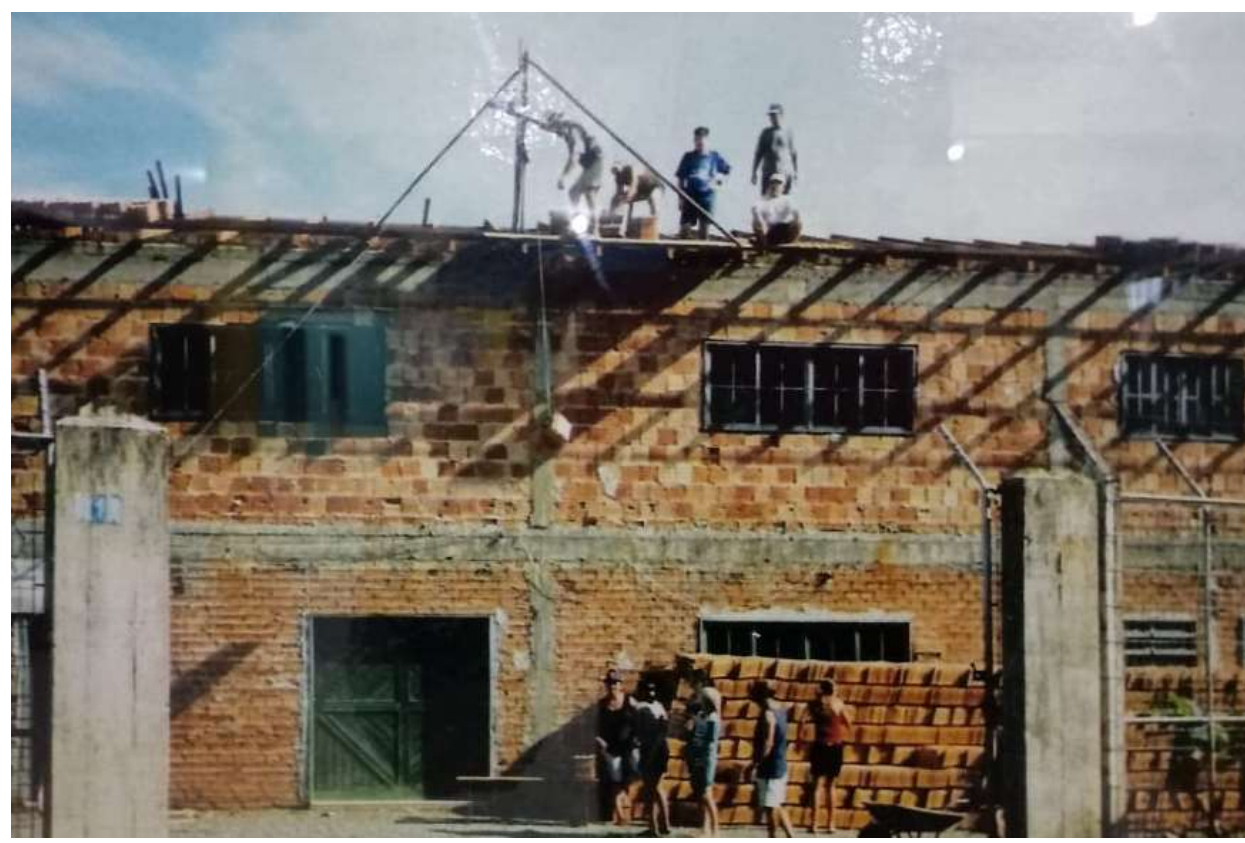

Fonte: Acervo Amorabi cedido aos autores.

Durante cerca de 10 anos, a Amorabi funcionou de forma completamente voluntária, sem recursos públicos para executar seus projetos, onde o teatro comunitário foi marcante para interação e diálogo entre a comunidade, sendo não apenas uma forma de entretenimento cultural, mas também um instrumento de conscientização política.

Somos um grupo que fazemos teatro comunitário e teatro político. Somos fruto deste trabalho da associação. Quando a gente lá na década de 80 resolve montar um CEl, resolve montar essa educação comunitária, nós estamos fazendo uma ação política, estamos fazendo inclusive $o$ trabalho do poder público né. (FRANÇA, 2021)

Após o ano de 2008, quando a Amorabi foi reconhecida como Ponto de Cultura pela Fundação Catarinense de Cultura, os editais públicos da associação passam a ser aprovados, possibilitando a realização de atividades gratuitas para a comunidade, como apresentações e curso de teatro, aulas de karatê, capoeira, costura, curso preparatório para o Exame Nacional de Jovens e 
voos, Charles Henrique; RIBAS, Bruna Eloise Taborda. A influência da educação popular freireana na Associação dos Moradores e Amigos do Bairro Itinga em Joinville/SC. PragMATIZES - Revista Latino-Americana de Estudos em Cultura, Niterói/RJ, Ano 12, n. 22, p. 328-350, mar. 2022.

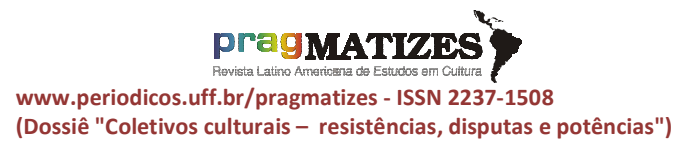

Adultos, eventos como sarais, de cestas básicas, roupas, produtos de manifestações da cultura popular, higiene, móveis etc. já foram prestadas apresentações musicais, oficinas, pela associação, que está sempre bazares e diversas ações dialogando e vivenciando com o povo, beneficentes, na sede da associação e na comunidade como um todo, envolvendo também as aldeias indígenas da região. Muitas doações para compreender suas necessidades e ajudar de forma consciente e politizada, e para não se limitar ao simples assistencialismo.

Figura -: Amorabi sempre presente em manifestações a favor dos direitos dos cidadãos

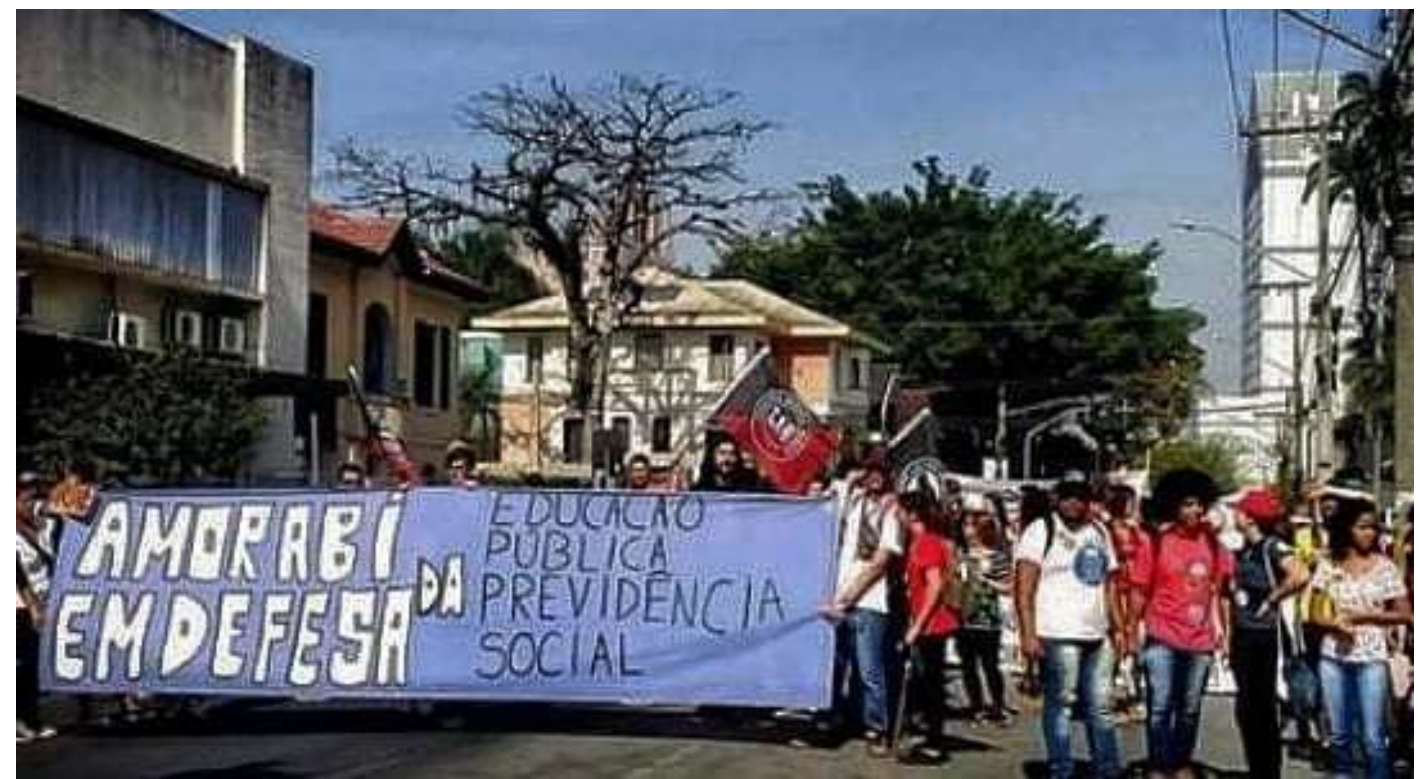

Fonte: https://www.facebook.com/Associacaoltinga. Acessado em 15 jul. 2021.

A atual presidenta da associação, Letícia Helena, que desde que estudava no CEI Vovó Juliana tem sua história envolvida com a Amorabi, afirma que

[...] a educação ela se dá para além do espaço formal, vamos dizer assim né, ou seja, com CEl, com as professoras na sala, mas nestes outros vários espaços né seja nos cursos, seja na própria vivência da associação. Então acredito que a educação na amorabi ela está envolvida em vários ângulos, em vários pedaços desse nosso corpo assim. (MAIA, 2021).

Durante os últimos anos a juventude tem ocupado espaços de liderança na associação, que vem 
dialogando cada vez mais com os movimentos sociais e expandindo suas ações para além dos arredores da Amorabi. Em 2016, a associação começa a se aproximar dos moradores do Residencial Trentino 1, e do coletivo PinteLute, que já realizava ações no local desde 2015.

O Trentino fica a 2 quilômetros de distância da associação, na zona limítrofe entre os bairros Escolinha e Itinga. Trata-se de um conjunto habitacional do programa Minha Casa Minha Vida, em parceria com a Caixa Econômica Federal e gerenciado pela Secretaria Municipal de Habitação, inaugurado em 2012 com o intuito de solucionar um problema social de moradia na cidade. Porém, os apartamentos, de menos de 50 metros quadrados que poderiam abrigar confortavelmente no máximo quatro pessoas, possuem famílias com cerca de sete integrantes residindo.

A estrutura física dos prédios também é precarizada, constantemente o abastecimento de gás e de água é comprometido, o tratamento de esgoto apresenta problemas recorrentes e três incêndios iniciados por curto-circuito já aconteceram no local. Com problemas

quase que inerentes às periferias, fica evidente que o poder público, fortemente influenciado pelo setor empresarial, não busca uma real solução para a questão habitacional na cidade, onde "a desigualdade persiste e a segregação socioespacial se mantém intacta" (VOOS, 2016, p. 78).

No ano de 2016, os militantes do coletivo Pintelute, que hoje também integram a Associação de Moradores do Itinga, estiveram presentes na ocasião de um incêndio. O fogo destruiu grande parte do apartamento de um casal com sete filhos, e a Defesa Civil interditou todo o bloco, impedindo os moradores de entrarem em suas casas. Sem ter para onde ir, muitas famílias abrigaram-se no salão de festas do condomínio, dividindo um espaço limitado para dormir e organizando uma cozinha comunitária, enquanto aguardaram por uma semana a devolutiva da Caixa e da Secretaria da Habitação (na época os apartamentos ainda estavam na garantia). A Amorabi e outros movimentos contribuíram com doações de cestas básicas, colchões e cobertores, e articularam com os moradores a realização de uma manifestação em frente ao 
Centreventos Cau Hansen, onde

As "aulinhas", como são acontecia a Feira da Sapatilha, uma das atrações do Festival de Dança.

Este foi apenas um dos momentos em que a Amorabi e o PinteLute estiveram presentes na luta juntamente com os moradores do Trentino, e durante esta conjuntura a preocupação com as crianças sempre foi preponderante, e as atividades que mais renderam e rendem frutos dessa parceria foram as aulas de artes, de teatro e capoeira voltada para as crianças e adolescentes do Itinga e do Trentino.

\section{"As Aulinhas" e o Pensamento Freireano}

Eles fazem de tudo para deixar você alegre e se sentir de casa, tipo confortável e eu aprendi bastante lá.

(Katia ${ }^{3}, 14$ anos)

Para Paulo Freire (2014, p. 20), "você só trabalha realmente em favor das classes populares se você trabalha com elas, discutindo com respeito seus sonhos, seus desejos, suas frustrações, seus medos, suas alegrias".

\footnotetext{
${ }^{3}$ Nomes fictícios para preservar a identidade das crianças/adolescentes.
}

crianças que participam, fazem parte de uma educação popular que desde o início teve a intenção de partir da realidade e do contexto da comunidade, dos reais interesses das crianças e adolescentes, suas inquietações e seus saberes, e onde, durante todo o projeto, as experiências foram moldando e conduzindo a execução das atividades.

Quando em 2015, o coletivo de muralismo político, PinteLute, formado por militantes (sendo a maioria professores e estudantes de licenciatura) decide iniciar um trabalho de base na comunidade do Trentino, as primeiras ações foram exibições de filmes com debates, realizadas no salão de festas. Tudo organizado e divulgado com parceria entre moradores e apoiadores de fora da comunidade.

Após algumas práticas, percebeu-se uma maior aproximação e interesse por parte do público infantil, então os filmes selecionados passaram a ser voltados para eles. As últimas exibições foram seguidas por produções de desenhos, que posteriormente evoluíram para oficinas 
de desenho, onde as crianças aprendiam o passo-a-passo para desenhar os personagens e superheróis que gostavam. Depois outras técnicas começaram a ser incorporadas e mais brincadeiras motoras, o que transformou estas oficinas nas "aulinhas de artes". Estas aulas aconteciam no próprio salão de festas e nos espaços do residencial, todos os sábados.

Com pouca experiência pedagógica e muita vontade de aprender, estes educadores buscaram ampliar seu repertório de atividades com os professores de teatro da Amorabi, que começaram a participar das aulinhas de artes, onde faziam diversas brincadeiras teatrais e trouxeram muito da cultura popular para agregar aos saberes das crianças. Eles levaram à comunidade o Mestre Fernando, estudioso das manifestações culturais, para ensinar para as crianças a dança do pau-defita e o cacuriá. Também foram realizadas oficinas de cordel, boi de mamão, e várias atividades com temática folclórica.

Outra experiência muito rica que os educadores da Amorabi proporcionaram para as crianças do Trentino foi a visita do escritor Otávio Jr, do Rio de Janeiro, autor da obra "O Livreiro do Alemão", onde o mesmo realizou uma roda de conversa, contação de história e oficina de poesia com as crianças das aulinhas.

Através desta parceria, as crianças e adolescentes do Trentino começaram a frequentar mais a Amorabi e participar dos cursos de capoeira e teatro oferecidos lá no espaço, como também oficinas de cultura popular e várias outras atividades. 
Figura 3 - Pau-de-fita com Mestre Fernando no Trentino

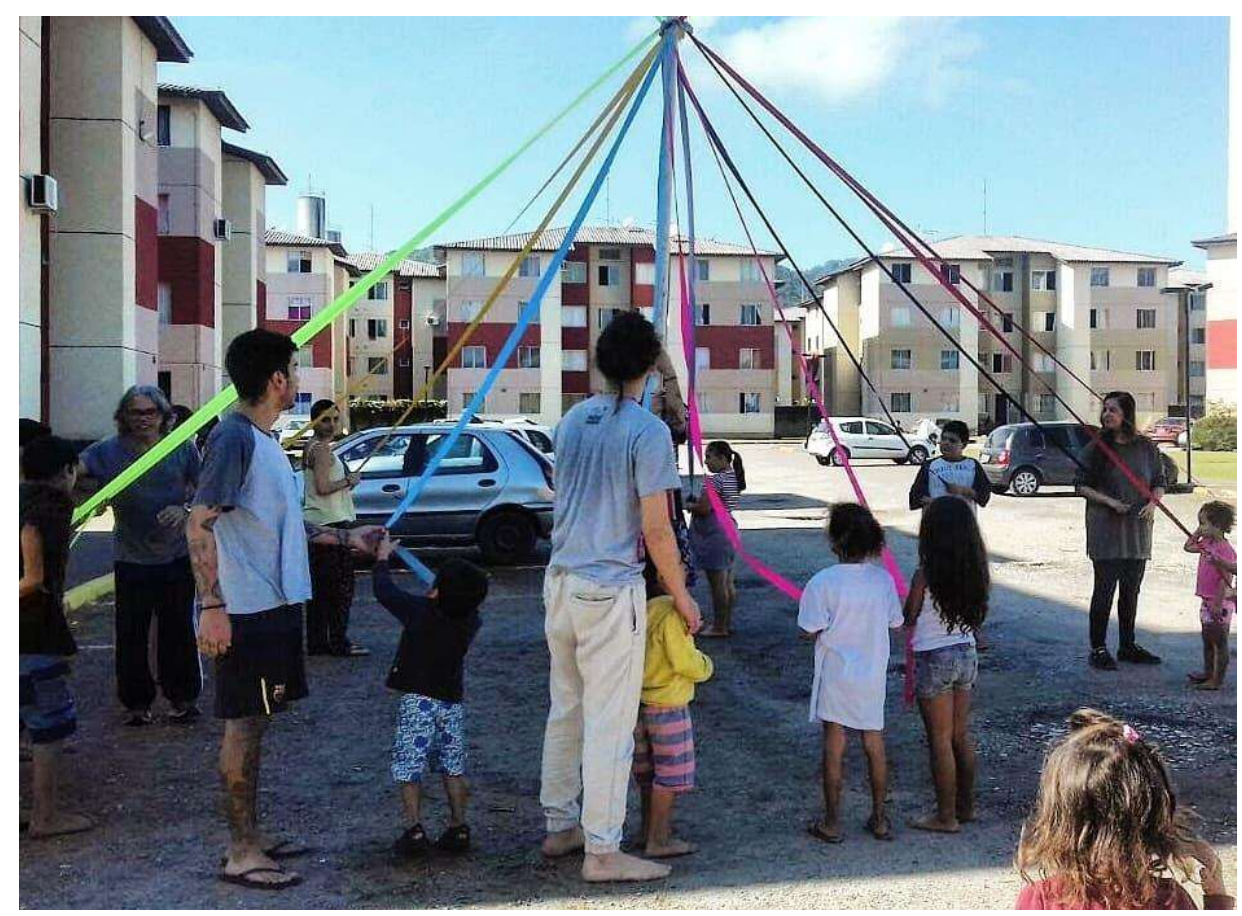

Fonte: Acervo pessoal.

Figura 4 - Contação de história com o autor Otávio Júnior

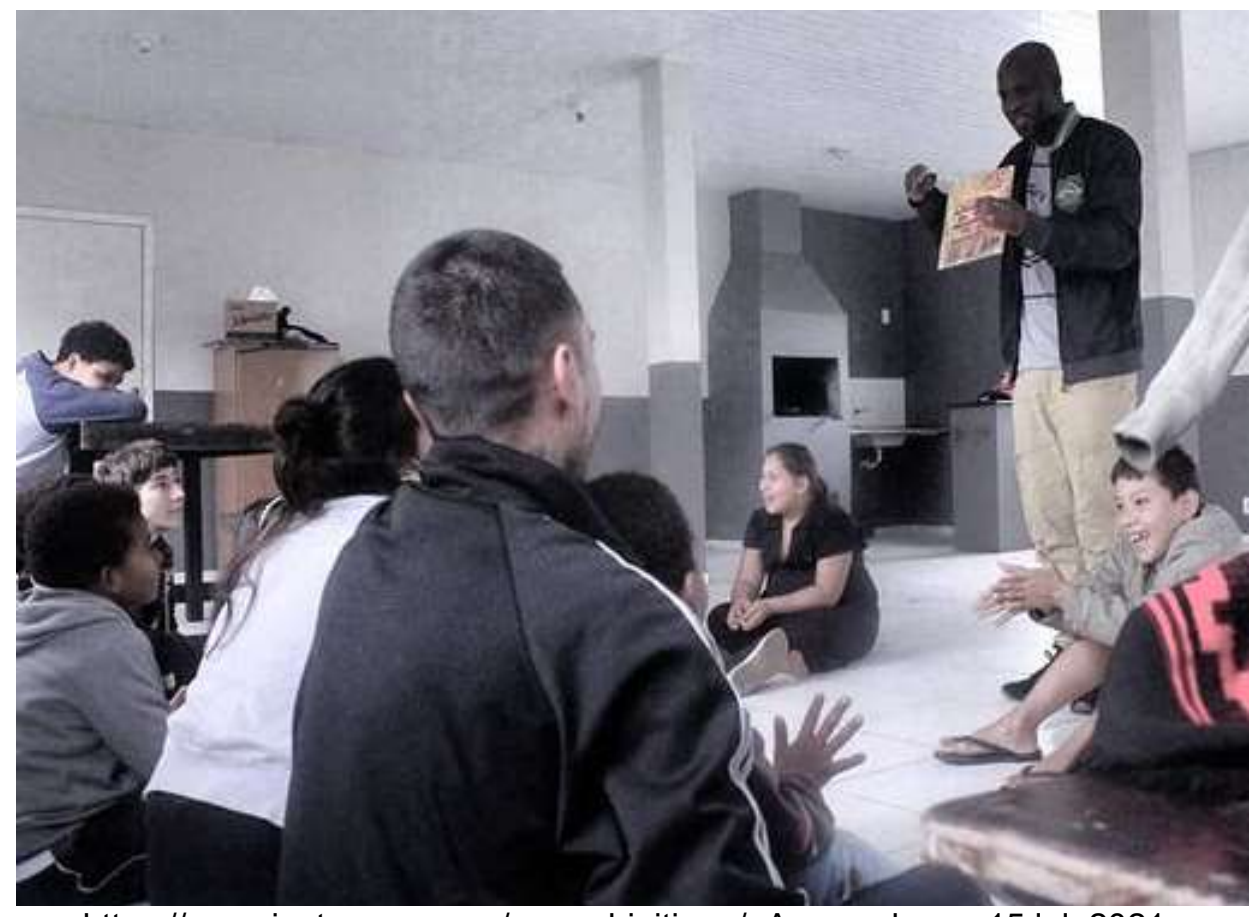

https://www.instagram.com/amorabi_itingal. Acessado em 15 jul. 2021. 
Figura 5 - Apresentação da peça "É o Tren", na UDESC em Florianópolis

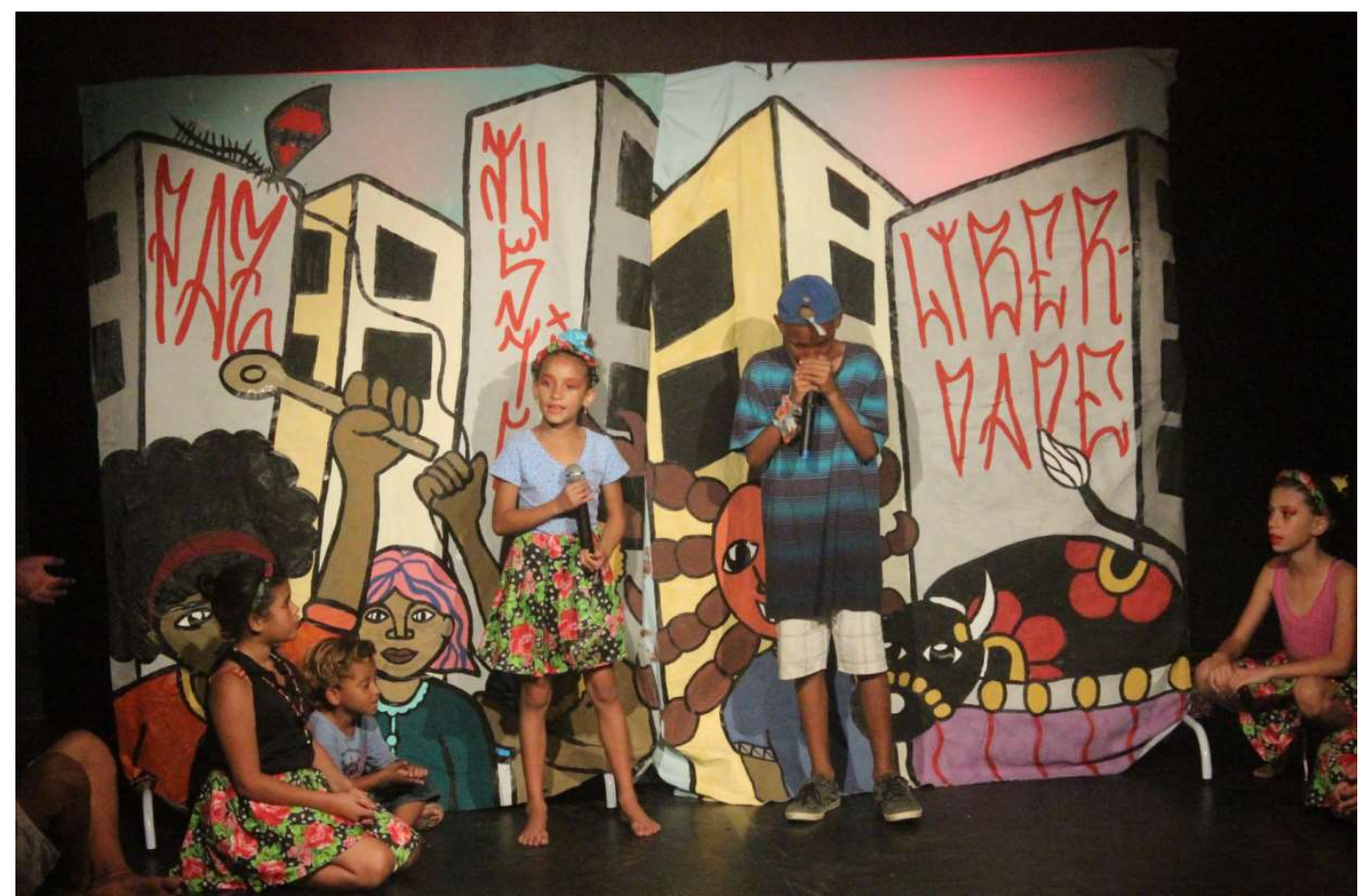

Fonte: https://www.facebook.com/Associacaoltinga. Acessado em 15 jul. 2021.

Além de toda essa diversidade que veio a agregar ao repertório cultural das crianças do Trentino, sempre buscou-se interseccionalizar com o conhecimento cultural que já partia o repertório deles, como por exemplo o funk. "A questão da identidade cultural, de que fazem parte a dimensão individual e a de classe dos educandos cujo respeito é absolutamente fundamental na prática educativa progressista, é problema que não pode ser desprezado" (FREIRE, 2016, p. 42).
Um dos exemplos de atividade que surgiram a partir das ideias dos alunos foi a gravação do clipe de uma paródia. As crianças recorrentemente pediam para que os educadores dessem aulas de maracatu, uma manifestação cultural pernambucana, que já tinha sido apresentada e experienciada por eles. Então em uma das aulas de artes (que já estavam acontecendo em parceria com a Amorabi) foi proposto que as crianças escrevessem uma paródia, reivindicando que 0 maracatu acontecesse, e a partir de um funk que 
escreveram, foi produzido um videoclipe. Após alguns meses, as aulas de maracatu começaram a ser realizadas na Escola Municipal Pauline Parucker, onde as crianças da comunidade estudam.

$\mathrm{Na}$ entrevista realizada com David ${ }^{1}, 14$ anos, que é morador do Trentino e participante ativo de diversas atividades da Amorabi, ele relata:

A atividade que mais teve relação em minha vida foi a atividade que nós fizemos sobre o Pantera Negra, onde nós fizemos as máscaras do Pantera Negra, e também fizemos o teatro do Pantera Negra. Essa foi a que mais teve relação com o meu diaa-dia.

$\mathrm{Na}$ ocasião citada pelo entrevistado, foram realizadas diversas atividades que se estenderam por algumas semanas, envolvendo 0 super-herói Pantera Negra, desde a exibição do filme e confecção de máscaras de papel machê (etapas realizadas no Trentino), à escrita de uma poesia sobre o tema, ensaios e apresentação (realizada no espaço de teatro da Amorabi). Durante todo este processo foi dialogada a questão racial envolvida na representatividade do super-herói negro, onde as crianças e adolecentes que participaram puderam, enxergando-se pertencente àquela representatividade, expressar um sentimento de auto-estima e empoderamento.

Aqui é o Trentino, tipo Wakanda, somos tudo Pantera Negra Aqui não passa nem 'os cana' Tamo na Amorabi, pra mandar um som

Pantera Negra de verdade aqui é tudo irmão

[...]

Nós canta, nós dança, nós fala em rima

Nós respeita todo mundo

Então respeita as mina

Eu gosto de preto porque é a minha cor

Os brancos se acham muito mas eles não tem amor

(Trecho da poesia composta pelos alunos) 
Figura 6 - Apresentação do "Rap do Pantera Negra", no Sarau de 1º de Maio, realizado em 2018 na Amorabi

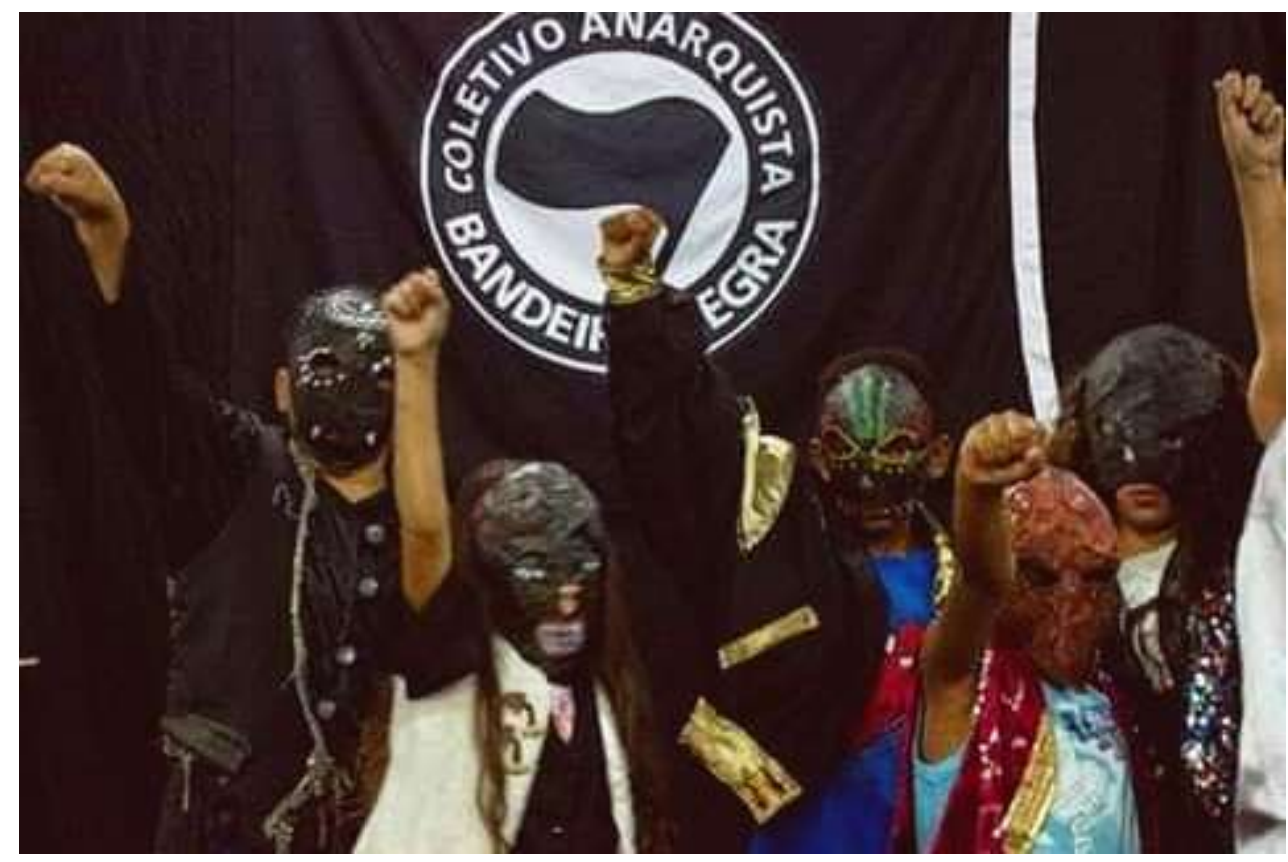

Fonte: https://www.instagram.com/amorabi_itinga/. Acessado em 15 jul. 2021.

Além de trabalhar a criatividade, escultura, pintura, leitura, escrita e atuação, as crianças e adolescentes que participaram desta atividade puderam refletir, expressar-se e discutir sobre aquilo que os oprime.

Segundo Freire, (2016, p.41), "Está errada a educação que não reconhece na justa raiva, na raiva que protesta contra as injustiças, contra a deslealdade, contra o desamor, contra a exploração e a violência, um papel altamente formador". Ainda conforme as palavras de Freire (2014, p. 111), "o educador progressista é leal à radical vocação do ser humano para a autonomia, e se entrega aberto e crítico à compreensão da posição de classe, de sexo e de raça para a luta de libertação".

Conscientes desse quadro, os educadores da Amorabi atuam politicamente para que as crianças e adolescentes desenvolvam sua consciência crítica através de referências próprias. A importância que a associação tem neste processo de politizar as minorias é notável, tanto por parte da militância como também dos próprios participantes diretos. $\mathrm{Na}$ 
VooS, Charles Henrique; RIBAS, Bruna Eloise Taborda. A influência da educação popular freireana na Associação dos Moradores e Amigos do Bairro Itinga em Joinville/SC. PragMATIZES - Revista Latino-Americana de Estudos em Cultura, Niterói/RJ, Ano 12, n. 22, p. 328-350, mar. 2022.

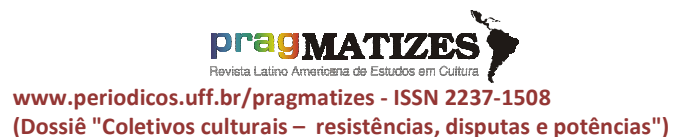

(Dossiê "Coletivos culturais - resistências, disputas e potências") visão da Contramestra Karla Reis, professora de capoeira da associação,

A amorabi em si é um local extremamente político, todas as ações da amorabi são políticas. Não consigo enxergar esse espaço fora dessa concepção. $E$ de uma forma positiva, extremamente positiva né. Porque eu vejo que a gente tem aí uma política negativa e a positiva, e a forma da amorabi se colocar politicamente é extremamente positiva, tem só a agregar, não é a toa que está aí a tantos anos. (REIS, 2021).

Para Letícia, professora de teatro e presidenta da Amorabi,

A política tá presente nas nossas ações. Não uma política partidária né, inclusive isso é até vedado dentro do nosso estatuto, mas a política em si. Nós somos seres políticos, nós pensamos politicamente, nós agimos. Então fazer política é necessário, tanto nas lutas pelas reivindicações do bairro, as questões de políticas públicas na área da educação, na área da cultura, acho que está presente no nosso respirar, no nosso caminhar aqui dentro, fazermos política. (MAIA, 2021).

Para Danilo, aluno da capoeira, educador de artes no Trentino e tesoureiro da Associação, as atividades da Amorabi "servem como espaços de conexão e convivência entre todos nós e essas atividades reverberam em tudo que fazemos ao longo da nossa vida. E criam uma autoestima de nos reconhecermos como uma comunidade". (MENDOZA, 2021).

Investigando sobre a educação popular freireana dentro da Amorabi, é possível realizar várias conexões entre a teoria e a prática. A professora de capoeira relata que não tinha conhecimentos muito aprofundados sobre a teoria de Paulo Freire, porém,

A filosofia dele faz parte da filosofia da amorabi com certeza. A minha forma de ensinar eu percebi que é através deste pensamento pedagógico freireano, né porque é a forma da gente conseguir atrair nossas crianças, nossos adolescentes, nossos jovens, pra proposta que a gente tá oferecendo. (REIS, 2021)

O professor de teatro e aluno da capoeira, João França, fala sobre a relação das suas práticas com o que Freire chamou de Pedagogia do Oprimido:

A questão da pedagogia do oprimido né, nós estamos aqui na associação, aqui na periferia de joinville, nós lidamos com diversas situações né, com crianças e principalmente adolescentes que estão por exemplo no processo da descoberta da sua sexualidade e acabam colocando as suas opressões né, e como a gente encontra meios da liberdade dentro disso. (FRANÇA, 2021). 
voos, Charles Henrique; RIBAS, Bruna Eloise Taborda. A influência da educação popular freireana na Associação dos Moradores e Amigos do Bairro Itinga em Joinville/SC. PragMATIZES - Revista Latino-Americana de Estudos em Cultura, Niterói/RJ, Ano 12, n. 22, p. 328-350, mar. 2022.

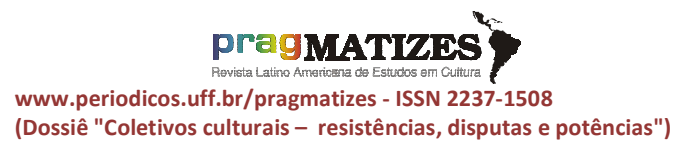

Quando indagada sobre a influência de Paulo Freire, a presidenta da associação afirma:

Eu tenho muita admiração, acho que é uma das principais referências pedagógicas de educação que a gente tem, sobre uma educação emancipadora, uma educação para a liberdade, que realmente envolva um pensamento crítico sobre as coisas, então eu acredito que ela esteja sim em vários espaços e atuação da associação assim frente a luta, seja de reivindicações, seja de espaços, até na nossa sala de teatro existe um cartaz, uma foto dele. $E$ também tive experiência de alguns anos junto com o João, de ser professora de teatro ali na associação, e a gente sempre tentou trazer muito disso né trazer muito do diálogo né da escuta, através das aulas a consciência do porquê a gente tá fazendo aquilo, a consciência crítica. Embora eu acho que a gente possa estar muito mais dentro. Acho que temos muito ainda a aprender e colocar em prática dos ensinamentos que essa referência tem e nos deixou. (MAIA, 2021).

Apesar de não possuir uma metodologia sistemática, o modelo de educação popular vivenciado na Amorabi ao longo dos anos nas mais diversas ações, estão à serviço da cidadania e da emancipação da sua comunidade.

O que quero dizer é que uma mesma compreensão da prática educativa, uma mesma metodologia de trabalho não operam necessariamente de forma idêntica em contextos diferentes. A intervenção é histórica, é cultural, é política. É por isso que insisto tanto em que as experiências não podem ser transplantadas mas reinventadas. [...] Daí a necessidade fundamental que tem o educador popular de compreender as formas de resistência das classes populares, suas festas, suas danças, [...] seus medos, suas semânticas, suas sintaxes, sua religiosidade. Não me parece possível organizar programas de ação político-pedagógicas sem levar seriamente em conta as resistências das classes populares. (FREIRE, 2014, p. 56 e 57)

Figura 7 - Cartaz colado na porta da sala de teatro da Amorabi

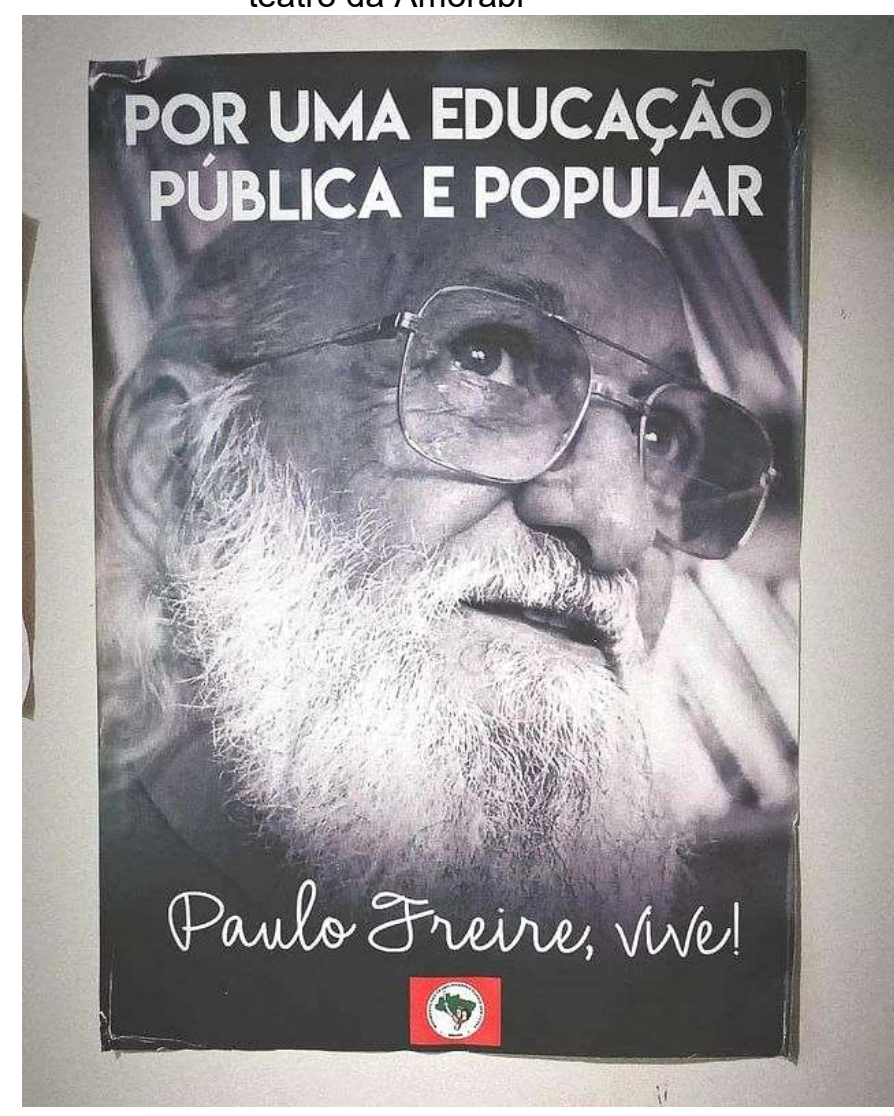

Fonte: Acervo Pessoal. 
Os alunos das Amorabi, quando questionados sobre a relevância das atividades da associação para seu desenvolvimento enquanto cidadão, responderam positivamente.

Isso memo. Eu considero que as atividades contribuiram ao meu desenvolvimento. Eu aprendi muitas coisas legais com as aulas da amorabi e com todos os outros professores. (DAVID', 2021).

\section{Para Danilo,}

Esse processo de estar alinhado com uma associação que tem a história de luta que a Amorabi tem, e ser uma das pontas pra dar a continuidade a essa história, ser aluno, professor, companheiro, é ser uma peça nessa engrenagem que se move pra um ideal de organização comunitária, de amor, ação direta, educação e afeto faz com que a gente cresça muito como ser humano e como cidadão. (MENDOZA, 2021).

Mesmo que a pandemia de Covid-19 tenha interrompido temporariamente a maioria das atividades, a Amorabi continua ativa e realizando arrecadação e distribuição de cestas básicas e cestas verdes para a comunidade, bem como para as aldeias e ocupações da região, que também são atendidas pela associação. Durante a pandemia também foi iniciado um projeto de produção de sabão artesanal, que recicla óleo de cozinha usado, revertendo em doações de sabão para a comunidade, ação muito relevante principalmente no contexto de prevenção ao coronavírus. Ou seja, a luta não pára. As demandas e possibilidades mudam e a ação política continua. Eis o exemplo de trabalho de base educacional, político e consistente que toda cidade e todo bairro necessita para possíveis melhorias na qualidade de vida da sociedade.

\section{Considerações Finais}

A riqueza e relevância do legado de Paulo Freire para a educação deveria ser algo indiscutível na nossa sociedade, levando em consideração que suas maiores contribuições estão de acordo com as concepções de direitos humanos, de igualdade, liberdade, autonomia, vida digna. Porém é necessário ainda hoje estudá-lo e defendê-lo, visto que toda concepção anti capitalista de educação é rejeitada pelo Estado.

Refletindo sobre a educação popular freireana $\mathrm{e}$ analisando a história de luta política da Amorabi, é 


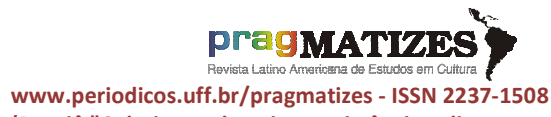

(Dossiê "Coletivos culturais - resistências, disputas e potências") possível encontrar muitas relações e influências, desde a sua fundação, participação comunitária, trabalho de base, conquista de direitos e melhorias, até a prestação de serviços à comunidade através da educação e da cultura.

Tendo como referências as pesquisas bibliográficas, as respostas dos questionários e as fotos coletadas, obteve-se um relato valioso sobre práticas significativas e comprometidas com a emancipação humana, produzidas pelos educadores $\mathrm{e}$ educadoras, alunos e alunas da Amorabi. Concluiu-se que as atividades propostas por eles não seguiam uma metodologia de projeto sistemática, que tivesse como base a educação popular freireana, porém todas as suas ações convergem com as teorias estudadas, bem como percebem Paulo Freire como uma referência pedagógica, que influencia direta e indiretamente na sua luta política dentro da comunidade.

A Associação de Moradores e Amigos do Itinga tem tanta potência transformadora, que se cada bairro seguisse este modelo de organização, aconteceria uma verdadeira revolução cultural na cidade de Joinville.
Esta pesquisa foi de grande importância para registro e documentação das vivências de educação popular, principalmente na comunidade do Trentino. Trazer à tona a inter-relação existente entre esta prática e a teoria de Paulo Freire e refletir sobre ela, pode ser o pontapé inicial para pesquisas mais aprofundadas nesta temática, e até mesmo para a criação de novos projetos estruturados na associação, tendo sempre em vista o objetivo maior de transformação social $\mathrm{e}$ liberdade para todo e qualquer ser humano.

\section{Referências bibliográficas}

BRASIL. Lei de Diretrizes e Bases da Educação Nacional, LDB. 9394/1996.

BURLAN, Cristiano. Paulo Freire, Um Homem no Mundo. Ep 2: As 40 horas de Angicos. Serviço Social do Comércio Sesc São Paulo, 2019. Disponível em: https://sesctv.org.br/programas-eseries/paulo-freire/. Acesso em: 01 set 2020.

FREIRE, Paulo. Pedagogia da Autonomia: Saberes Necessários à Pratica Educativa. Rio de Janeiro: Paz e Terra, 2016.

FREIRE, Paulo. Pedagogia do Oprimido. Edição especial. [Saraiva de Bolso]. Rio de Janeiro: Nova Fronteira, 2012. 
FREIRE, Paulo. Política e Educação.

São Paulo: Paz e Terra, 2014.

GAGLIOTI, Patrícia Stahl. Quando a

Arte Sopra - O papel cultural da

Amorabi e da Casa Iririú. Secretaria de

Cultura e Turismo de Joinville, 2019.

Disponível em:

youtube.com/watch?v=mmbUD2DBAI4

. Acesso em: 14 mar. 2021.

GIL, Antônio Carlos. Métodos e técnicas de pesquisa social. São Paulo: Atlas, 2008.

GOHN, Maria da Glória. Retrospectiva sobre a educação popular e os movimentos sociais no Brasil. Movimento: Rev. de Educação, Niterói, ano 4, n. 7, p. 10-32, jul./dez, 2017. Disponível em: https://periodicos.uff.br/revistamovimen to/article/download/32624/18759.

Acesso em: 05 maio 2020.

PETRY, Cristóvão. O Teatro em Comunidades Periféricas. Uma trajetória desenvolvida no bairro Itinga (Joinville-SC). Joinville: Areia, 2020.

PRADO, Windson. Moradores do Trentino fazem protesto neste domingo, no $34^{\circ}$ Festival de Dança de Joinville. Jornal ND Notícias do Dia, 24 jul 2016. Disponível em: https://ndmais.com.br/danca/moradore s-do-trentino-fazem-manifestacaodurante-o-34o-festival-de-danca-dejoinville/. Acesso em: 01 maio 2021.

SEMIS, Laís. Vivi o Estado Novo e passei pela ditadura, mas nunca vi um período tão assustador como este na Educação. Revista Nova Escola, 10 jan 2019. Disponível em: https://novaescola.org.br/conteudo/150 04/vivi-o-estado-novo-e-passei-peladitadura-mas-nunca-vi-um-periodo-taoassustador-como-este-na-educacao.

Acesso em: 01 set. 2020. $\begin{array}{lrrr}\text { STRECK, } & \text { Danilo } & \text { R.. } & \text { Entre } \\ \text { emancipação } & \text { e } & \text { regulação: }\end{array}$ (des)encontros entre educação popular e movimentos sociais. Revista Brasileira de Educação [online]. 2010. Disponível em: http://www.scielo.br/scielo.php?pid=S1 413$24782010000200007 \&$ script=sci_abstr act\&tlng=pt. Acesso em: 07 abr. 2020.

VoOS, Charles Henrique. Quem Manda Nesta Cidade? Poder e rentseeking urbano em Joinville/SC após o Estatuto da Cidade. Porto Alegre: 2016. 